\section{Second-order fixed-ratio schedules}

\author{
D. E. BLACKMAN, G. V. THOMAS, and N. W. BOND \\ University of Nottingham, Nottingham, England
}

Six pigeons were exposed to chained and tandem fixed-ratio schedules in which this ratio requirement in each of the 10 components was one [FR 10 (FR 1)]. The results obtained suggest similarities between a conventionally defined unit of behavior, such as a single keypeck, and the sequences of schedule-controlled behavior, which are treated as unitary responses in other second-order schedules.

Kelleher (1966) has proposed that some complex sequences of schedules and stimuli be described as "second-order schedules." Such a schedule he defines as "one in which the behavior specified by a schedule contingency is treated as a unitary response that is itself reinforced according to some schedule of primary reinforcement." Thus, he quotes the example of the schedule which specifies that primary reinforcement is contingent upon the completion of three successive fixed-interval 2-min components and denotes this as FR 3 (FI 2). If no exteroceptive stimulus changes occur between the beginning of a sequence and the primary reinforcement, this is further defined as a tandem schedule [tand FR 3 (FI 2)]. If, however, a different exteroceptive stimulus is associated with each of the FI components, the second-order schedule is defined as chained [thus, chain FR 3 (FI 2)]. The tandem schedule has been used as a convenient control for evaluating the functions of the stimuli programmed in the corresponding chain schedule, and it has been found that a significant feature of extended chain schedules is the comparatively low rate of responding that occurs in the initial components (e.g., Findley, 1962; Kelleher, 1966). However, no definitive experiment has investigated extended chain and tandem schedules in which the requirement in each component is in fact a conventionally defined unit of behavior, i.e., a single keypeck, FR 1 . The present experiment was designed to do this.

\section{SUBJECTS}

Six male pigeons with previous experimental histories only of a VI $30-\mathrm{sec}$ schedule of positive reinforcement were maintained at approximately $85 \%$ of their free-feeding body weights.

\section{APPARATUS}

A standard experimental chamber for pigeons was used (Ferster \& Skinner, 1957). This chamber contained a response key which could be illuminated by a multiple-stimulus projector (Grason-Stadler Model E4580A). Located directly below the response key was a feeder which gave a

$3-\mathrm{sec}$ access to grain for reinforced responses. The chamber could be illuminated by two 1.W houselights. Each peck to the key was recorded and produced an audible feedback click. The experiment was programmed by conventional relay and timing apparatus located in a separate room, and continuously present white noise masked most other extraneous sounds. The results were recorded on a cumulative recorder, digital counters, and a cumulative timer.

\section{PROCEDURE}

Each bird was tested daily, and each session terminated after 42 reinforcements.

Since the schedules used might be expected to generate high response rates, three of the birds were exposed to a procedure by which their responses were spaced; this was to facilitate an analysis of interresponse times. The spacing procedure used was based on the findings of Neuringer \& Schneider (1968), that prolonged feedback stimuli after nonreinforced responses decrease response rates without otherwise affecting the overall pattern of behavior controlled by FR and FI schedules. Thus for these three birds (P23, P24, and P25), each nonreinforced response was followed by a $1-\mathrm{sec}$ period when all the lights in the experimental chamber were extinguished (blackout). For the remaining three birds (P26, P27, and P28), each nonreinforced response was followed by a similar blackout, but of only 0.05 -sec duration. Data up to the second reinforcement in each session have been discarded, as some Ss showed a "warm-up" effect.

\section{Chain Condition}

All Ss were initially exposed to a 10-component chain schedule with FR 1 in each component [chain FR 10 (FR 1)]. The 10 components in the chain were each correlated with a different exteroceptive stimulus, and the sequence of 10 stimuli used is shown in Fig. 1. In each of Stimuli 10.2 , a single response produced a blackout period as described above, followed by the next stimulus in the sequence. A response in Stimulus 1 was followed by reinforcement, during which the feeder aperture was illuminated and the house and key lights were darkened. After 20 sessions' exposure to this chain schedule, the behavior of all $\mathrm{Ss}$ had stabilized.

\section{Tandem Condition}

The basic schedule in this condition was tand. FR 10(FR 1). Blackouts occurred after each response, and every 10th response was followed by reinforcement, as before. However, Stimulus 1 from the previous chain condition was now presented in each component. After behavior had restabilized on this tandem schedule (17 sessions), the chain schedule was reintroduced to recover the original performance.

\section{RESULTS}

Mean overall response rates for each bird individually on the chained and tandem schedules are shown in Table 1. In

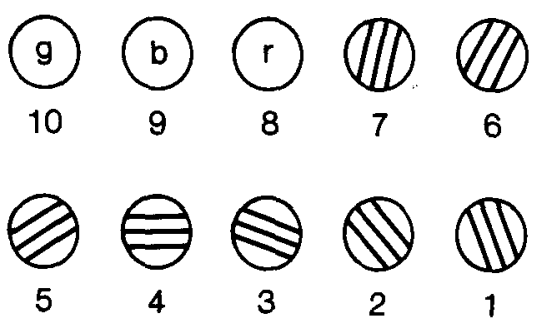

Fig. 1. The sequence of exteroceptive stimuli used in the chained schedule, numbered in reverse order up to reinforcements. None of the Ss had ever been exposed to any of these stimuli in its previous experimental history. $g=$ green; $\mathrm{b}=$ blue; $\mathrm{r}=$ red; other stimuli, black bars on white ground.

Table 1

Mean Overall Response Rates for Each Bird Individually from the Final Six Sessions of Each Exposure to the Chained and Tandem Schedules. All values are in responses per minute: standard deviations (SD) are shown in brackets.

\begin{tabular}{|c|c|c|c|c|c|c|}
\hline \multirow[b]{2}{*}{ Subject } & \multicolumn{2}{|c|}{$\begin{array}{c}\text { Chain } \\
\text { Virst Exposure }\end{array}$} & \multicolumn{2}{|c|}{ Tandem } & \multicolumn{2}{|c|}{$\begin{array}{c}\text { Chain } \\
\text { Second Exposure }\end{array}$} \\
\hline & Mean & $\mathrm{SD}$ & Mean & $\mathrm{SD}$ & Mean & SD \\
\hline P23 & 54.9 & $(1.6)$ & 45.7 & $(3.0)$ & 52.8 & (2.2) \\
\hline $\mathrm{P} 24$ & 25.8 & (2.2) & 40.9 & $(5.5)$ & 30.7 & (2.9) \\
\hline P25 & 27.2 & $(4.9)$ & 52.9 & (3.5) & 35.0 & (5.1) \\
\hline $\mathrm{P} 26$ & 127.8 & $(16.7)$ & 164.6 & (5.4) & 148.1 & $(6.0)$ \\
\hline $\mathrm{P} 27$ & 163.3 & $(7,3)$ & 170.2 & (5.8) & 141.3 & $(9.5)$ \\
\hline P28 & 143.4 & $(3.1)$ & 116.3 & (7.1) & 123.8 & (12.3) \\
\hline
\end{tabular}



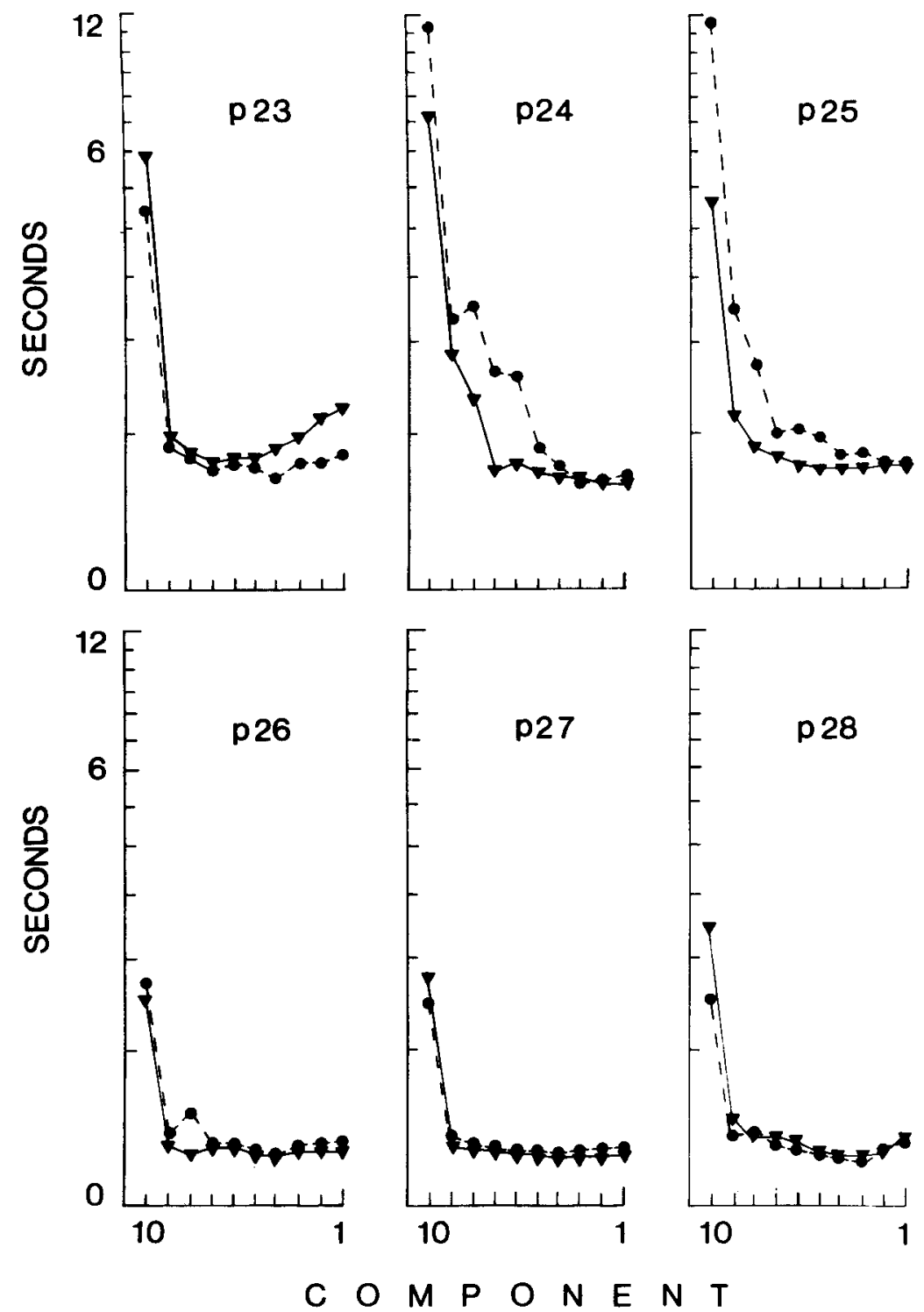

Fig. 2. Average response latencies in each component of the chained and tandem schedules. The components are numbered in reverse order up to reinforcement (i.e., reinforcements followed a response in Component 1). $\Delta-\Delta:$ tandem; $\bullet-. \bullet$ : chain. (Note log scale on ordinate.)

calculating response rates, the time for which the experimental box was darkened (during reinforcements and during the response feedback stimuli) has been eliminated. A Mann-Whitney $U$ test was used to compute the probabilities associated with the differences between overall response rates for each bird on the chained and tandem schedules. In every case these probabilities were less than 0.02 (two-tailed).

The time that elapsed between the start of a component and the bird making a response (response latency) for each component on the chained and tandem schedules is shown in Fig. 2. Each data point represents an average value derived from 240 determinations of each latency over the final six sessions of each schedule. Data from only the first exposure to the chained schedule are presented, although performance on the second exposure to this schedule was essentially similar.

Representative cumulative records of the performance of P25 on both the chained and tandem schedules are presented in Fig. 3. These records also show the long pauses that occasionally occurred after reinforcement in the initial components of the chained schedule.

\section{DISCUSSION}

Table 1 shows that the response spacing procedure was effective in reducing overall response rates, for P23, P24, and P25 all responded at a considerably lower rate than any of the other three birds throughout the experiment. Table 1 also shows that for all birds the response rate during the tandem schedule differed significantly from the rate of responding during the chain schedules. However, the direction of this change was not consistent, P23 and P28 showing a reduction, but the other four birds an increase, in response rate on the tandem schedule.

Figure 2 presents these experimental data in more detail and shows the mean latency between the offset of a feedback stimulus and the subsequent response for each component in the two schedule conditions. The general configuration of these latencies through the sequence is similar to those reported by Davison (1969) for simple FR schedules [effectively, tand. FR x (FR 1)]. Thus, longer latencies characterize the initial components (10), reflecting postreinforcement pausing.

In comparing the chain and tandem conditions for each bird, it may be seen in Fig. 2 that the overall latencies reflect the differences in response rates outlined in Table 1. With P26, P27, and P28, there is a small, but consistent, difference between chain and tandem conditions for each bird, and with the birds exposed to the longer feedback stimulus (P23, P24, and P25), these differences are magnified.

It has been noted that P23 and P28 differed from the other $S s$ in that they responded more slowly on the tandem schedule than on the chain. Figure 2 suggests an additional difference between these two birds and the other four; with P23 and P28 there is a tendency for latencies to decrease to a minimum at an intermediate component and then to increase towards the reinforced component, while the other four Ss tended not to show this terminal increase in latencies. Both sorts of configuration have been reported previously, and Davison (1969) has suggested that increasing

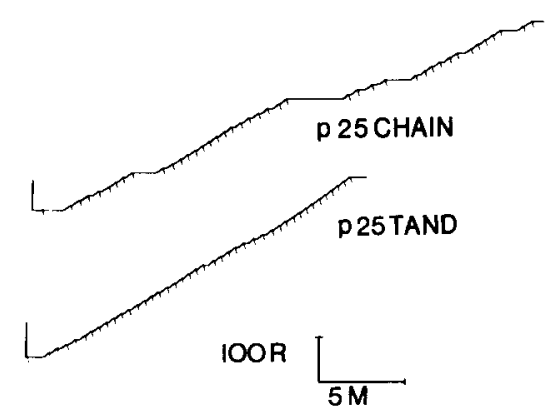

Fig. 3. Cumulative records of P25 on chained and tandem schedules. The recorder pen is deflected at reinforcement. $R$ : responses; $M$ : minutes. 
latencies (when they occur) reflect investigation of the food-hopper by the S. Observation in the present experiment did not confirm this suggestion. but we note some similarities between this configuration and the interresponse times reported on FR schedules with continuous added counters (Ferster \& Skinner, 1957). Technically, such schedules are chain FR x (FR 1); however, it is not easy to interpret such schedules in this way because the discriminability of the stimulus changes involved is difficult to specify. An additional point is that these stimulus changes usually occur along a given dimension (e.g., width of slit), which may introduce a further unevaluated effect.

To summarize, four of the $S$ s in the present experiment provide data similar to those produced from other chained and tandem schedules. In particular, the occasional prolonged pauses after reinforcement, illustrated in Fig. 3, are similar to the breakdown in behavior often observed on other extended chains. This supports the view that the sequences of behavior reinforced by second-order schedules may be regarded as unitary responses essentially similar to the more conventionally defined units of behavior used in the present experiment. Two $\mathrm{Ss}$ in this experiment do not support this generalization, for they responded more slowly on the tandem schedule; however, they also appeared to differ in at least one other respect, i.e., configuration of latencies through the sequence. Similar configurations have occasionally been reported before, both with simple FR schedules (Davison, 1969) and with FR schedules with added counters (Ferster \& Skinner, 1957).

\section{REFERENCES}

DAVISON, M. C. Successive interresponse times in fixed-ratio and second-order fixed-ratio performance. Journal of the Experimental Analysis of Behavior, 1969, 12, 385-389.

FERSTER, C. B., \& SKINNER, B. F. Schedules of reinforcement. New York: Appleton-Century-Crofts, 1957.

FINDLEY, J. D. An experimental outline for building and exploring multi-operant behavior repertoires. Journal of the Experimental Analysis of Behavior, 1962, 5, 113-166.

KELLEHER, R. T. Chaining and conditioned reinforcement. In W. K. Honig (Ed.), Operant behavior: Areas of research and application. New York: Appleton-Century-Crofts, 1966. Pp. 160-212.

NEURINGER, A. J., \& SCHNEIDER, B. A. Separating the effects of interreinforcement time and number of interreinforcement responses. Journal of the Experimental Analysis of Behavior, 1968, 11, 661-667. attack. The opportunity to attack is evidently reinforcing, since a response was acquired when the opportunity to aggress was made contingent on the response and extinguished when this contingency was removed. Aggression was considered to be a distinct motivational state in the same sense that hunger has been considered a motivational state. It was concluded that it is rewarding to aggress in the motivational state created by the shock "for the duration of stimulation and for a brief period after the cessation of stimulation [Azrin et al, 1965, pp, 179-180]."

Azrin, Hutchinson, \& Sallery (1964) report that the probability of attack in monkeys gradually diminished after the shock until it reached zero several moments later. The probability of attack in the first $1.5 \mathrm{sec}$ after the shock was .95 , while after $12 \mathrm{sec}$ the probability approached zero. In their study the object of aggression was always available. Similarly, Azrin, Rubin, \& Hutchinson (1968) found an inverse relation between biting of an inanimate object by rats and time since shock, but again the object of aggression was always present. The question that prompted the present study was: Will the drive state induced in an animal by an aversive stimulus (foot-shock) persist over time in the absence of an object of aggression?

\section{SUBJECTS}

The Ss were eight albino rats derived from the Sprague-Dawley strain and obtained from Dublin Animal Laboratories in Virginia. The average weight of the animals was $260 \mathrm{~g}$, with a range of $219-302 \mathrm{~g}$. They were all approximately 90 days old at the start of the experiment. The animals were paired together randomly and given 20 preliminary shocks to accustom them to the experimental arrangement and to ascertain if all animals were fighters. Two animals appeared to be nonfighters and were replaced. The failure to find fighting behavior in monkeys has been previously noted (Azrin, Hutchinson, \& Hake, 1963; Azrin et al, 1965), but no one has reported failing to find fighting in rats. The present failure may be due to the use of generally docile Sprague-Dawley rats.

Pain-elicited fighting behavior in rats is a well-known, highly reliable phenomenon (Ulrich, 1967). Ulrich \& Azrin (1962) at first suggested that, "The consistent elicitation of the fighting response by aversive stimulation without prior conditioning appears to be best defined as an unconditional reflex [p. 519]." This "fighting reflex" was suggested to be similar, in a general way, to the unconditioned salivary reflex to food.
Recent studies on fighting behavior in primates have resulted in a different interpretation of pain-induced fighting. Azrin, Hutchinson, \& McLaughlin (1965) found that monkeys in the presence of aversive stimulation will learn to perform an instrumental response (pulling a chain) in order to obtain an object of aggression (a tennis ball). Thus, pain seems to create a changed motivational state in the animal in which it is reinforcing for the animal to
*This study was conducted while the authors were students at Washington and Lee University with funds from the R. E. Lee Research Fund for undergraduate research. The invaluable assistance of David G. Elmes and Joseph B. Thompson is gratefully acknowledged. Thanks are also expressed to Robert G. Crowder and William C. Holz for their critical remarks on an earlier version of this manuscript.

TPresently in the U.S. Army at Ft. Sam Houston, Texas. 